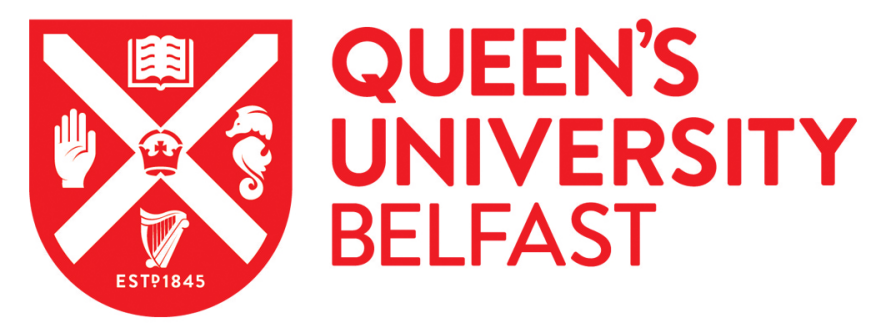

\title{
Alcohol consumption and cardiovascular disease: differential effects in France and Northern Ireland. The Prime Study
}

Marques-Vidal, P., Montaye, M., Arveiler, D., Evans, A., Bingham, A., Ruidavets, J., Armouyel, P., Haas, B., Yarnell, J., Ducimetiere, P., \& Ferrieres, J. (2004). Alcohol consumption and cardiovascular disease: differential effects in France and Northern Ireland. The Prime Study. European Journal of Cardiovascular Prevention and Rehabilitation, 11(4), 336-343.

Published in:

European Journal of Cardiovascular Prevention and Rehabilitation

Queen's University Belfast - Research Portal:

Link to publication record in Queen's University Belfast Research Portal

\section{General rights}

Copyright for the publications made accessible via the Queen's University Belfast Research Portal is retained by the author(s) and / or other copyright owners and it is a condition of accessing these publications that users recognise and abide by the legal requirements associated with these rights.

Take down policy

The Research Portal is Queen's institutional repository that provides access to Queen's research output. Every effort has been made to ensure that content in the Research Portal does not infringe any person's rights, or applicable UK laws. If you discover content in the Research Portal that you believe breaches copyright or violates any law, please contact openaccess@qub.ac.uk. 


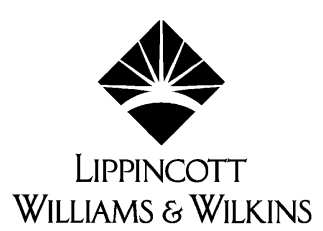

\title{
Alcohol consumption and cardiovascular disease: differential effects in France and Northern Ireland. The PRIME study Pedro Marques-Vidal ${ }^{a}$, Michèle Montaye ${ }^{b}$, Dominique Arveiler ${ }^{c}$, Alun Evans ${ }^{d}$, Annie Bingham ${ }^{\mathrm{e}}$, Jean-Bernard Ruidavets ${ }^{\mathrm{a}}$, Philippe Amouyel ${ }^{\mathrm{b}}$, Bernadette Haas $^{c}$, John Yarnell ${ }^{d}$, Pierre Ducimetière ${ }^{e}$ and Jean Ferrières ${ }^{a}$
}

\author{
aINSERM U558, Faculté de Médecine Purpan, Toulouse, ' INSERM U508, Institut Pasteur de Lille, \\ Lille, 'MONICA-Strasbourg, Laboratoire d'Epidémiologie et de Santé Publique, Strasbourg, France, \\ ${ }^{\mathrm{d} B e l f a s t-M O N I C A}$, The Department of Epidemiology and Public Health, The Queen's University \\ of Belfast, Belfast, UK and 'INSERM U258, Hôpital Paul Brousse, Villejuif, France.
}

Received 12 November 2003 Revised 12 May 2004 Accepted 20 May 2004

Background The effects of wine and other alcoholic beverages on coronary heart disease (CHD) have seldom been studied in several countries using a common methodology.

Design Five-year prospective study conducted among 9750 men (7352 in France and 2398 in Northern Ireland) free of CHD at entry. Outcomes were angina pectoris, myocardial infarction or CHD death.

Results In all, $90 \%$ of subjects in France reported drinking at least once per week, versus $61 \%$ in Northern Ireland. In France, after adjusting for other CHD risk factors, subjects in the highest quartile of alcohol consumption had a significantly lower risk of developing angina pectoris relative to non-drinkers. For myocardial infarction and all CHD events, the risk also decreased from the first to the fourth quartile $(P$ for trend $=0.02)$. Conversely, in Northern Ireland, no significant relationship was found between alcohol consumption and the incidence of angina pectoris or all CHD events, although alcohol consumption appeared to decrease the risk for myocardial infarction. Similar findings were obtained when the 5\% higher alcohol consumers were excluded from the analysis. Finally, splitting the alcohol consumption into wine, beer and spirits did not improve the relationships, the three types of beverage exerting comparable effects on CHD events.

Conclusions Alcohol consumption patterns exert differential effects on CHD risk in middle-aged men from France and Northern Ireland. Further, the amount of alcohol consumption, rather than the type of alcoholic beverage, is related to both angina pectoris and myocardial infarction in France, whereas no relationship was found in Northern Ireland. Eur $J$ Cardiovasc Prev Rehabil 11:336-343 (c) 2004 The European Society of Cardiology.

European Journal of Cardiovascular Prevention and Rehabilitation 2004, 11:336-343

Keywords: incidence, myocardial infarction, angina pectoris, prospective, alcohol consumption, men

\section{Introduction}

Coronary heart disease (CHD) is one of the main causes of premature death in industrialized countries [1], and its prevalence has been increasing in developing countries $[2,3]$. Moderate alcohol consumption has been shown to be inversely related to the incidence of coronary artery

Correspondence and requests for reprints to Jean Ferrières, MD, MSC, FESC INSERM U558, Faculté de Médecine, Département, d'Epidémiologie, 1er étage, 37, Allées Jules Guesde, 31073 Toulouse cedex, France.

Tel: + 3356152 1870; fax: + 33562264240 ;

e-mail: jean.ferrieres@cict.fr disease [4-9], but whether the protective effect of wine is superior to that of other alcoholic beverages remains arguable [6,10-14]. Furthermore, although the impact of alcohol intake on myocardial infarction (MI) or coronary death has been thoroughly studied, little is known about its effect on angina pectoris. Due to its specific characteristics, the PRIME study (Prospective Epidemiological Study of Myocardial Infarction) enables the assessment of the impact of alcohol consumption and the different types of alcoholic beverages on the incidence of angina pectoris, MI and CHD death in middle-aged, 
healthy men living in France and Northern Ireland, two countries with contrasting rates of coronary heart disease and patterns of alcoholic beverage consumption [15].

\section{Patients and methods Population sampling}

The PRIME study was established in 1991 in the populations of four collaborating WHO-MONICA centres in Belfast (UK), Lille, Strasbourg and Toulouse (France) [16]. The target was to recruit 2500 men, aged 50-59 years, in each centre and to follow them for a minimum of 5 years.

\section{Personal and medical history}

Self-administered questionnaires relating to demographic, socio-economic factors and diet were completed at home by the participants and checked by an interviewer at the clinic. Data on level of education, occupational activity, personal and family history, tobacco consumption, drug intake and physical activity were collected. Diabetic treatment was recorded for dietary and drug therapy, whereas only drug therapy for hyperlipidaemia and hypertension was considered. Vigorous exercise was defined as a hard physical (sports) activity (leading to sweating, increased heart rate) over a minimum of $20 \mathrm{~min}$, at least once per week.

Subjects were considered free of CHD at entry if no criterion among the following three was met: (a) reported MI and/or angina pectoris diagnosed by a physician; (b) electrocardiographic evidence of MI, defined as major or moderate $Q$ waves on Minnesota coding [17]; and (c) a positive answer to the Rose Chest Pain questionnaire [17].

\section{Clinical data}

Blood pressure was measured once at the end of the examination after a 5 -min rest in the sitting position. Measurements were performed with an automatic device (Spengler SP9), which also recorded heart rate. A standard cuff size was used, but a large cuff was available when necessary. At least three measuring devices were available at any time in each centre and all three were used equally. In order to avoid systematic differences between centres, the devices were circulated among them. The devices were also recalibrated every 3 months at the Co-ordinating Centre in Paris.

\section{Alcohol consumption}

Alcohol consumption was assessed by a validated questionnaire that recorded the subjects mean consumption (in units) of wine, beer, cider and spirits for each day of the week [18,19]. Intake of alcohol (expressed in $\mathrm{ml}$ of pure ethanol/week) was estimated from the average number of millilitres of ethanol in one unit of each type of alcoholic beverage: wine (10 or $12 \%$ alcohol vol/ vol $)=12 \mathrm{cl}$ serving; beer $(5 \%$ alcohol $)=12 \mathrm{cl}$ serving; beer $(6$ or $8 \%$ alcohol $)=25$ or $33 \mathrm{cl}$ serving; $\operatorname{cider}(5 \%$ alcohol $)=12 \mathrm{cl}$ serving; spirits $(20$ or $40 \%$ alcohol $)=2$ or $6 \mathrm{cl}$ serving. Subjects were considered as former drinkers if they reported no current alcohol consumption but indicated they had consumed alcohol (for any period of time).

\section{Blood sampling and assay procedures}

Venous blood was collected into siliconized vacutainer tubes (Vacutainer; Becton Dickinson) containing EDTA. Plasma total cholesterol and triglyceride levels were measured by enzymatic methods using reagents from Boerhinger Mannheim (Mannheim, Germany).

\section{Follow-up}

Subjects were contacted annually by letter and a clinical event questionnaire was completed. For all subjects reporting a possible clinical event, clinical information was sought directly from hospital or general practitioner notes. All details of electrocardiograms (ECGs), hospital admissions, enzymes, surgical interventions, angioplasties, treatment, etc., were collected and classified according to MONICA criteria [20]. Death certificates were searched for supporting clinical and post-mortem evidence of cause of death. A medical committee was established, comprising members of each PRIME centre and three independent cardiologists (two from France and one from the UK).

Myocardial infarction was defined by one of the following sets of conditions: (a) new $Q$ wave or other new typical aspect of necrosis at ECG; (b) typical or atypical symptoms and new (or increased) ischaemia at ECG and myocardial enzymes greater than twice the upper normal limit; and (c) post-mortem evidence of fresh MI or thrombosis.

Coronary death was defined by death with a definite or probable coronary cause or sudden death. Definite coronary death was defined as death with a documented event. Possible coronary death was defined as suspected coronary death with no other documentation or another explanation. Sudden death was defined as death occurring within $1 \mathrm{~h}$ following symptoms without explanation. 'Hard' CHD cases were defined as coronary deaths or non-fatal MI.

Angina pectoris was defined by the presence of resting or stress chest pain and at least one of the following criteria: (a) angiographic stenosis over 50\%; or (b) a positive scintigraphy (if no angiographic data); or (c) positive exercise stress test (if no angiographic or scintigraphic data); or (d) ECG changes at rest (if no angiographic, scintigraphic or exercise stress test data), but without all criteria for MI and no evidence for a non-coronary cause 
in the clinical history. Unstable angina was defined as a crescendo pain (change in frequency or severity of stress chest pain or appearance of rest chest pain to pre-existing stress pain) or rest pain with either enzyme changes or ECG changes. Total CHD events were defined as all subjects with at least one diagnosis of non-fatal MI or angina pectoris, or CHD death.

\section{Statistical analysis}

Of the initial 10600 subjects, 842 were excluded due to a history of CHD, and of the remaining 9758 , eight were excluded due to missing data. Statistical analysis was conducted using SAS (SAS Institute, Cary, North Carolina, USA) software. Myocardial infarction was counted only once, whether or not preceded by angina events. Conversely, angina events were counted once but only when they were not preceded by myocardial infarction. The impact of total alcohol consumption and according to the type of beverage on the 5-year incidence of CHD events was assessed by multivariate logistic regression. For hypertension, adjustment was performed on presence of any anti-hypertensive drug treatment (dichotomous variable: Yes/No) and on blood pressure levels (systolic and diastolic, as continuous variables). A similar procedure was made for hyperlipidaemia: presence of any hypolipidaemic drug treatment (also dichotomous variable) and on cholesterol and triglycerides (as natural logarithm). For France, an adjustment on study centre was also performed. In the last models, the effect of alcohol intake coming respectively from wine, beer and spirits on the relative risks was supposed to be multiplicative without interaction. Results were expressed as mean \pm standard deviation (SD), as percentages and (number of subjects) or as adjusted relative risks and (95\% confidence interval).

\section{Results \\ Clinical characteristics of subjects}

Overall, 9750 subjects were included in the analysis: 7352 in France and 2398 in Northern Ireland. Their clinical characteristics according to alcohol consumption

Table 1 (a) Baseline risk factors according to level of alcohol intake, France

\begin{tabular}{|c|c|c|c|c|c|c|}
\hline Alcohol intake (ml/wk) & None & $0<.<128$ & $128 \leq .<265$ & $265 \leq .<441$ & $\cdot \geq 441$ & $\begin{array}{c}P \text { between-group } \\
\text { comparison }\end{array}$ \\
\hline$n$ & 693 & 1667 & 1658 & 1654 & 1680 & \\
\hline Age & $54.9 \pm 2.8$ & $54.9 \pm 2.9$ & $54.8 \pm 2.9$ & $55.0 \pm 3.0$ & $55.0 \pm 2.8$ & 0.66 \\
\hline Body mass index $\left(\mathrm{kg} / \mathrm{m}^{2}\right)$ & $26.5 \pm 3.8$ & $26.6 \pm 3.5$ & $26.5 \pm 3.3$ & $26.5 \pm 3.2$ & $27.2 \pm 3.6$ & 0.0001 \\
\hline \multicolumn{7}{|l|}{ Smoking (\%) } \\
\hline Never & 240 (35) & 597 (36) & $538(32)$ & $397(24)$ & $265(16)$ & \\
\hline Past & $299(43)$ & $769(46)$ & $755(46)$ & $778(47)$ & $775(46)$ & 0.001 \\
\hline Current & $154(22)$ & $301(18)$ & $365(22)$ & $479(29)$ & $640(38)$ & \\
\hline Systolic BP & $131 \pm 18$ & $132 \pm 18$ & $132 \pm 17$ & $134 \pm 18$ & $137 \pm 19$ & 0.0001 \\
\hline Diastolic BP & $83 \pm 13$ & $84 \pm 11$ & $83 \pm 11$ & $84 \pm 11$ & $86 \pm 12$ & 0.0001 \\
\hline Hypertension (\%) & $190(27)$ & $444(27)$ & $430(26)$ & $475(29)$ & 552 (33) & 0.001 \\
\hline Total cholesterol & $206 \pm 36$ & $216 \pm 35$ & $219 \pm 36$ & $222 \pm 36$ & $227 \pm 41$ & 0.0001 \\
\hline HDL cholesterol & $45 \pm 12$ & $47 \pm 12$ & $49 \pm 12$ & $51 \pm 13$ & $53 \pm 14$ & 0.0001 \\
\hline Triglycerides & $131 \pm 73$ & $132 \pm 76$ & $134 \pm 90$ & $139 \pm 91$ & $160 \pm 128$ & 0.0001 \\
\hline Hyperlipidaemia (\%) & $126(18)$ & $403(24)$ & $395(24)$ & $452(27)$ & 591 (35) & 0.001 \\
\hline Diabetes (\%) & $35(5)$ & $48(3)$ & $45(3)$ & $31(2)$ & $41(2)$ & 0.001 \\
\hline Married (\%) & $566(82)$ & $1496(90)$ & $1478(89)$ & $1460(88)$ & $1469(87)$ & 0.001 \\
\hline Years of school & $10 \pm 5$ & $12 \pm 4$ & $12 \pm 4$ & $12 \pm 3$ & $11 \pm 3$ & 0.0001 \\
\hline Vigorous exercise (\%) & $172(25)$ & 568 (34) & 570 (34) & $556(34)$ & $501(30)$ & 0.001 \\
\hline
\end{tabular}

(b) Baseline risk factors according to level of alcohol intake, Northern Ireland

\begin{tabular}{|c|c|c|c|c|c|c|}
\hline Alcohol intake (ml/wk) & None & $0<.<114$ & $114 \leq .<227$ & $227 \leq .<414$ &.$\geq 414$ & $\begin{array}{c}P \text { between-group } \\
\text { comparison }\end{array}$ \\
\hline$n$ & 946 & 375 & 349 & 371 & 357 & \\
\hline Age & $54.8 \pm 2.9$ & $54.9 \pm 2.9$ & $54.8 \pm 2.9$ & $54.5 \pm 3.0$ & $54.4 \pm 2.8$ & 0.07 \\
\hline $\begin{array}{l}\text { Body mass index }\left(\mathrm{kg} / \mathrm{m}^{2}\right) \\
\text { Smoking }(\%)\end{array}$ & $26.2 \pm 3.4$ & $26.0 \pm 3.1$ & $26.2 \pm 3.4$ & $26.2 \pm 3.4$ & $26.1 \pm 3.5$ & 0.87 \\
\hline Never & $456(48)$ & $149(40)$ & $90(26)$ & $78(21)$ & 69 (19) & \\
\hline Past & $292(31)$ & 123 (33) & $128(37)$ & $147(40)$ & $113(32)$ & 0.001 \\
\hline Current & $198(21)$ & $103(27)$ & $130(37)$ & $146(39)$ & $175(49)$ & \\
\hline Systolic BP & $132 \pm 19$ & $132 \pm 20$ & $135 \pm 21$ & $136 \pm 20$ & $138 \pm 22$ & 0.0001 \\
\hline Diastolic BP & $81 \pm 11$ & $81 \pm 11$ & $82 \pm 11$ & $83 \pm 12$ & $84 \pm 12$ & 0.0001 \\
\hline Hypertension (\%) & $197(21)$ & $71(19)$ & $74(21)$ & $86(23)$ & $101(28)$ & 0.03 \\
\hline Total cholesterol & $223 \pm 38$ & $227 \pm 38$ & $232 \pm 41$ & $230 \pm 40$ & $231 \pm 40$ & 0.0002 \\
\hline HDL cholesterol & $43 \pm 11$ & $46 \pm 11$ & $47 \pm 12$ & $49 \pm 14$ & $51 \pm 15$ & 0.0001 \\
\hline Triglycerides & $163 \pm 92$ & $164 \pm 97$ & $169 \pm 81$ & $182 \pm 102$ & $204 \pm 167$ & 0.0001 \\
\hline Hyperlipidaemia (\%) & $356(38)$ & $149(40)$ & $172(49)$ & $186(50)$ & $169(47)$ & 0.001 \\
\hline Diabetes (\%) & $10(1)$ & $6(2)$ & $1(1)$ & $4(1)$ & $0(0)$ & not valid \\
\hline Married (\%) & $820(87)$ & $334(89)$ & $304(87)$ & $326(88)$ & $268(75)$ & 0.001 \\
\hline Years of school & $11 \pm 3$ & $12 \pm 3$ & $11 \pm 3$ & $11 \pm 3$ & $10 \pm 2$ & 0.0001 \\
\hline Vigorous exercise (\%) & $110(12)$ & $71(19)$ & $48(14)$ & 47 (13) & $39(11)$ & 0.005 \\
\hline
\end{tabular}

Results are expressed as mean \pm SD or as number of subjects and (\%). BP, blood pressure; HDL, high-density lipoprotein. 
are summarized in Tables $1 \mathrm{a}$ for France and $1 \mathrm{~b}$ for Northern Ireland.

In France, over $90 \%$ of subjects reported drinking. Subjects in the highest quartile of alcohol consumption had significantly higher body mass index (BMI), nondrinkers reported diabetes more frequently, were less frequently married, and had less vigorous exercise than the other groups. Also, the increase in alcohol consumption was associated with an increase in the prevalence of smoking, hyperlipidaemia, higher blood pressure levels, higher total and high-density lipoprotein (HDL) cholesterol, and higher triglyceride levels (Table 1a).

In Northern Ireland, 39\% of subjects were non-drinkers. Subjects in the higher quartile of alcohol consumption were less frequently married and had less vigorous exercise than the other groups. As in France, the increase in alcohol consumption was associated with an increase in the prevalence of smoking, hyperlipidaemia, higher blood pressure levels, higher HDL cholesterol, and higher triglyceride levels (Table 1b). Higher alcohol consumption was also associated with lower educational level, whereas the higher total cholesterol was observed only after excluding the highest $5 \%$ of the alcohol consumption levels (Table 1b).

Effect of alcohol consumption on the incidence of CHD During follow-up there were 106 coronary deaths or MI and 94 angina pectoris events in France; the corresponding figures for Northern Ireland were 61 and 60; finally, the number of subjects who presented with a CHD event (angina pectoris, myocardial infarction, or coronary death) was $197(2.7 \%)$ in France and $121(5 \%)$ in Northern Ireland.

In France, subjects in the higher quartile of alcohol consumption had a significant lower risk of developing angina pectoris relative to non-drinkers, and this difference remained significant after adjusting for other cardiovascular risk factors (Table 2). For myocardial infarction, the risk decreased from the first to the fourth quartile $(P$ for trend $=0.02$, alcohol treated as a continuous variable, non-drinkers included) and remained significant after multivariate adjustment (drinkers versus non-drinkers, $P=0.001$ ). When all CHD events were pooled, alcohol consumption was associated with a decreased risk (drinkers versus non-drinkers: $P=0.01)$, the third and fourth quartiles having the lowest risk ( $P$ for trend $=0.005$ ) (Table 2). Those findings were further confirmed when total cholesterol and triglycerides were replaced by low-density lipoprotein (LDL) cholesterol and the relationships even strengthened when the top 5\% of alcohol distribution was excluded from the analysis (not shown). Finally, no significant differences were found regarding the effect of centre (not shown).

In Northern Ireland, no significant relationship was found between alcohol consumption and the incidence of angina pectoris or all CHD events, although alcohol consumption appeared to decrease the risk for MI (Table 2). Similar findings were obtained when the 5\% highest alcohol consumers were excluded from the analysis or when total cholesterol and triglycerides were replaced by LDL cholesterol in the multivariate model (not shown).

Since abstainers reported more frequently being on sick leave or possible alcohol-related diseases (all types of digestive cancer, liver illness and gastric illness), a further analysis was performed after excluding those subjects (Table 3). Similar findings were obtained when the data was analysed using a proportional hazards regression (not shown). No significant changes were noted relative to Table 2, and similar findings were obtained after further adjustment on any other type of disease (not shown).

\section{Effect of the type of alcoholic beverage on the incidence of CHD}

The effect of the type of alcoholic beverage on the incidence of CHD events was quantitatively assessed and

Table 2 Relative risks for angina pectoris, myocardial infarction and all coronary heart disease (CHD) events according to level of alcohol intake, France and Northern Ireland

\begin{tabular}{|c|c|c|c|c|c|c|c|}
\hline \multirow[b]{2}{*}{ France } & \multicolumn{5}{|c|}{ Alcohol consumption ( $\mathrm{ml}$ ethanol/week) } & \multirow{2}{*}{$\begin{array}{c}P \text { value for any } \\
\text { drinking versus none }\end{array}$} & \multirow{2}{*}{$\begin{array}{l}P \text { value for trend } \\
\text { consumption }\end{array}$} \\
\hline & None & $0<.<128$ & $128 \leq .<265$ & $265 \leq .<441$ & $1: \geq 441$ & & \\
\hline Angina pectoris & 1 & $0.80(0.35-1.85)$ & $0.77(0.36-1.78)$ & $0.49(0.20-1.20)$ & $0.38(0.15-0.96)$ & 0.17 & 0.03 \\
\hline Myocardial infarction & 1 & $0.54(0.29-1.02)$ & $0.45(0.23-0.87)$ & $0.37(0.19-0.73)$ & $0.26(0.13-0.54)$ & 0.001 & 0.02 \\
\hline All CHD events & 1 & $0.74(0.45-1.21)$ & $0.65(0.39-1.08)$ & $0.48(0.28-0.81)$ & $0.37(0.22-0.64)$ & 0.01 & 0.005 \\
\hline Northern Ireland & None & $0<.<114$ & $114 \leq .<227$ & $227 \leq .<414$ &.$\geq 414$ & & \\
\hline Angina pectoris & 1 & $0.65(0.21-2.00)$ & $1.41(0.59-3.36)$ & $1.44(0.61-3.44)$ & $0.96(0.35-2.66)$ & 0.76 & 0.82 \\
\hline Myocardial infarction & 1 & $0.62(0.27-1.45)$ & $0.69(0.32-1.52)$ & $0.56(0.25-1.28)$ & $0.43(0.17-1.09)$ & 0.05 & 0.34 \\
\hline All CHD events & 1 & $0.67(0.36-1.27)$ & $0.81(0.46-1.46)$ & $0.88(0.50-1.54)$ & $0.70(0.38-1.29)$ & 0.20 & 0.72 \\
\hline
\end{tabular}

Results are expressed are relative risks (95\% confidence interval) adjusted for age, marital status (two groups), educational level (four groups), vigorous exercise, body mass index, systolic blood pressure, diastolic blood pressure, total cholesterol, triglycerides (Ln), smoking status (three groups), anti-hypertensive drug treatment and hypolipidaemic drug treatment. For France, a further adjustment on centre was performed.

*Alcohol considered as a continuous variable, non-drinkers included. 
Table 3 Relative risks for angina pectoris, myocardial infarction and all coronary heart disease (CHD) events according to alcohol intake, subjects on sick leave or with alcohol-related disease excluded

\begin{tabular}{|c|c|c|c|c|c|c|c|}
\hline \multirow[b]{2}{*}{ France } & \multicolumn{5}{|c|}{ Alcohol consumption ( $\mathrm{ml}$ ethanol/week) } & \multirow{2}{*}{$\begin{array}{c}P \text { value for any } \\
\text { drinking versus none }\end{array}$} & \multirow{2}{*}{$\begin{array}{l}P \text { value for trend } \\
\text { consumption }\end{array}$} \\
\hline & None & $0<.<128$ & $128 \leq .<265$ & $265 \leq .<441$ &.$\geq 441$ & & \\
\hline Angina pectoris & 1 & $0.67(0.29-1.56)$ & $0.67(0.29-1.56)$ & $0.36(0.14-0.93)$ & $0.34(0.13-0.85)$ & 0.07 & 0.04 \\
\hline Myocardial infarction & 1 & $0.59(0.30-1.17)$ & $0.50(0.25-1.00)$ & $0.42(0.21-0.85)$ & $0.27(0.13-0.59)$ & 0.006 & 0.03 \\
\hline All CHD events & 1 & $0.74(0.44-1.25)$ & $0.66(0.39-1.13)$ & $0.47(0.27-0.81)$ & $0.37(0.21-0.65)$ & 0.01 & 0.006 \\
\hline Northern Ireland & None & $0<.<114$ & $114 \leq .<227$ & $227 \leq .<414$ &.$\geq 414$ & & \\
\hline Angina pectoris & 1 & $0.65(0.21-2.03)$ & $1.36(0.57-3.27)$ & $1.47(0.61-3.50)$ & $1.04(0.38-2.84)$ & 0.73 & 0.67 \\
\hline Myocardial infarction & 1 & $0.61(0.26-1.84)$ & $0.68(0.31-1.47)$ & $0.57(0.25-1.30)$ & $0.43(0.17-1.09)$ & 0.05 & 0.36 \\
\hline All CHD events & 1 & $0.67(0.35-1.27)$ & $0.80(0.44-1.42)$ & $0.89(0.51-1.56)$ & $0.71(0.38-1.32)$ & 0.20 & 0.84 \\
\hline
\end{tabular}

Results are expressed are relative risks (95\% confidence interval) adjusted for age, marital status (two groups), educational level (four groups), vigorous exercise, body mass index, systolic blood pressure, diastolic blood pressure, total cholesterol, triglycerides (Ln), smoking status (three groups), anti-hypertensive drug treatment and hypolipidaemic drug treatment. For France, a further adjustment on centre was performed.

*Alcohol considered as a continuous variable, non-drinkers included.

Table 4 Effects of the type of alcoholic beverage on the incidence of coronary heart disease (CHD)

\begin{tabular}{|c|c|c|c|c|c|}
\hline & \multicolumn{4}{|c|}{ Alcoholic beverages } & \multirow[b]{2}{*}{ Total alcohol } \\
\hline & None & Wine & Beer & Spirits & \\
\hline \multicolumn{6}{|l|}{ Angina pectoris } \\
\hline France & 1 & $0.83(0.71-0.98)$ & $0.98(0.75-1.19)$ & $1.01(0.59-1.75)$ & $0.95(0.78-0.99)$ \\
\hline Northern Ireland & 1 & $0.38(0.08-1.87)$ & $0.99(0.83-1.13)$ & $1.06(0.95-1.40)$ & $1.06(1.02-1.28)$ \\
\hline \multicolumn{6}{|l|}{ Myocardial infarction } \\
\hline France & 1 & $0.88(0.78-1.00)$ & $0.89(0.58-0.99)$ & $1.09(0.95-1.58)$ & $0.95(0.80-0.98)$ \\
\hline Northern Ireland & 1 & $0.18(0.03-1.29)$ & $0.97(0.81-1.08)$ & $1.01(0.84-1.26)$ & $0.98(0.85-1.06)$ \\
\hline \multicolumn{6}{|l|}{ All CHD events } \\
\hline France & 1 & $0.89(0.82-0.98)$ & $0.94(0.74-1.01)$ & $1.04(0.83-1.43)$ & $0.96(0.84-0.97)$ \\
\hline Northern Ireland & 1 & $0.33(0.11-0.96)$ & $0.99(0.89-1.07)$ & $1.03(0.93-1.22)$ & $0.99(0.92-1.06)$ \\
\hline
\end{tabular}

Results from two different analyses conducted separately for each country: one using total alcohol (last column), another separating total alcohol into wine, beer and spirits (first columns). Results are expressed as relative risks ( $95 \%$ confidence interval) for one beverage unit (15 ml alcohol) per day adjusted for age, marital status (two groups), educational level (four groups), vigorous exercise, body mass index, systolic blood pressure, diastolic blood pressure, total cholesterol, triglycerides (Ln), smoking status (three groups), anti-hypertensive drug treatment and hypolipidaemic drug treatment. For France, a further adjustment on centre was performed.

the effect of one unit of beverage per day was reported. Table 4 provides the results from two different analyses conducted separately for each country: one using total alcohol (last column), another separating total alcohol into wine, beer and spirits (first columns). In France, the effect of wine, beer and spirits on CHD was relatively constant (Table 4), and splitting total alcohol consumption into wine, beer or spirits did not improve the model (likelihood chi-square with two degrees of freedom $=0.96,4.88$ and 1.61 for angina pectoris, MI and all CHD events, respectively, all non-significant). Also, in Northern Ireland, no significant effect of the type of alcoholic beverage was found for angina pectoris and myocardial infarction, although low relative risks were observed for wine consumption, which became statistically significant for prediction of all CHD events (Table 4). Finally, since former drinkers could bias the abstainer's group, subjects on sick leave or with possible alcohol-related diseases were excluded from the analysis, and no significant modifications of the relative risks were found (not shown).

\section{Discussion}

Few studies have focused on the effect of alcoholic beverages on the incidence of angina pectoris [21,22].
Also, little is known regarding the effect of alcoholic beverages on CHD events in France [23]. Due to its specific characteristics, the PRIME study enabled the assessment of the impact of alcohol consumption and the different types of alcoholic beverages on the incidence of angina pectoris, MI and CHD death in France and Northern Ireland, two countries with contrasting rates of coronary heart disease and patterns of alcoholic beverage consumption [15]. We decided to analyse the effects of alcohol consumption separately for France and Northern Ireland, because the drinking pattern as well as the relative amounts of each type of alcoholic beverage consumed differed greatly between the two countries: alcohol consumption was evenly distributed throughout the week with only a slight increase at weekends in France, whereas Fridays and Saturdays accounted for twothirds of total alcohol consumption in Northern Ireland [15]; also, wine was the predominant alcoholic beverage in France, whereas beer was the predominant beverage in Northern Ireland. Since the metabolic effects of alcohol can differ according to the pattern of intake [24], pooling the data from the two countries was considered inappropriate, as some of the effects attributed to alcohol consumption might in fact, be due to differences in patterns of intake between the two countries. 
In both countries, alcohol consumption was significantly related to an increase in blood pressure level, total and HDL cholesterol, and triglycerides. Those findings are in agreement with previously published data $[25,26]$. Thus, multivariate adjustment on those cardiovascular risk factors had to be performed in order to adequately assess the effects of alcoholic beverage consumption on CHD [27]. However, it has been claimed that most of the protective effect of alcohol consumption on cardiovascular disease is due to an increase in HDL cholesterol levels $[28,29]$. Consequently, in this study, we chose not to adjust on HDL cholesterol level, since it might have led to an over-adjustment. Still, even after adjusting for HDL cholesterol, alcohol consumption retained its protective effect in France, whereas no differences were found in Northern Ireland (not shown).

In France, after multivariate adjustment, alcohol consumption was significantly and inversely related to the incidence of angina pectoris and myocardial infarction. These findings thus confirm those from other studies $[21,22]$ where alcohol consumption was associated with a decrease in risk of both angina pectoris and myocardial infarction. However, the effect of alcohol consumption on MI risk seemed stronger than for angina pectoris; our data thus suggest that there may be some differential effect of alcohol consumption on the mechanisms of the two types of clinical complications. Indeed, angina pectoris has been related mainly to atherosclerotic disease, whereas MI has been related both to atherosclerosis and thrombosis. Since alcohol consumption, apart from its effects on HDL cholesterol level, also favourably influences fibrinogen and platelet aggregation $[10,30]$, it is likely that the impact of regular alcohol consumption is more pronounced on MI than on angina pectoris.

The relative risk for MI decreased with increasing alcohol consumption without any evidence of a threshold. Our findings replicate those of other studies [21,31]. Although no clear mechanism can be offered for such a finding, it could be speculated that the increase in HDL cholesterol levels, as well as the decrease in fibrinogen and platelet aggregation induced by alcohol consumption, might counterbalance the deleterious effects of the increase in smoking, triglyceride and blood pressure levels by alcohol intake within the range of alcohol consumption in this sample. Other possible explanations might be the relatively short follow-up period (5 years), which prevented the appearance of deleterious effects in the highest consumption groups or the small number of subjects reporting very high alcohol consumption.

Several hypotheses can be provided regarding the lack of relationship between total alcohol consumption and CHD events in Northern Ireland. First, the prevalence of drinkers was low, which led to a small number of events among drinkers. Also, as stated previously, the drinking pattern in Northern Ireland is different from that in France [15]. Since the effects of binge drinking appear to be more deleterious than those of continuous drinking $[32,33]$, it is likely that the protection conferred by a given amount of alcohol is greater if alcoholic beverages are consumed on a moderate but regular basis rather than in larger amounts over a short period of time. Further, we have shown that Northern Irish drinkers have higher blood pressure on Monday, which decreases until Thursday, whereas blood pressure levels are constant throughout the week for French drinkers [34]; thus, it is tempting to speculate that the rebound blood pressure changes after weekend drinking in Northern Ireland might negate the protective effect of alcohol consumption seen in France. Another possible hypothesis might be related to the small number of cases in Northern Ireland. Finally, as stated previously, since alcohol drinking is tightly related to the socio-cultural characteristics of the populations studied, it is probable that even after multivariate adjustment the specific effect of alcohol on CHD events cannot be established.

In this study, it was not possible to analyse separately beer and wine drinkers since in France $90 \%$ of beer drinkers also drank wine, and in Northern Ireland only a very small number of subjects $(n=94)$ drank wine exclusively. Thus, the effects of the different types of alcoholic beverages were estimated using a quantitative model without interaction. In this model, no significant differences were found between wine, beer and spirits on the incidence of CHD events in France, with only a possible protective effect of wine in Northern Ireland. Those findings are in agreement with other studies $[6,14,35]$, indicating that it is alcohol, rather than the type of alcoholic beverage, which mostly influence CHD events. Indeed, the stronger effect of wine relative to the other alcoholic beverages reported by several studies [10-12,36], might in fact be due to specific social and clinical characteristics of the subjects who consume wine.

Finally, due to the relatively small number of cases, it is possible that our study did not have sufficient power to discriminate meaningful differences between types of alcoholic beverages.

In this study, the multivariate analysis was conducted using logistic regression. Since there were very few subjects lost to follow-up, virtually all subjects (except those who died or presented with a CHD) completed the 5 -year study, and in this case, analysing the data with logistic regression or a proportional hazards (Cox) model leads to very similar results [37]. With a proportional hazards analysis, the results were almost identical to those of the logistic regression (not shown). 
Former drinkers represented the vast majority of the abstainers group (68\% in France and $46 \%$ in Northern Ireland), and excluding them from the analysis did not change the results in Northern Ireland and even strengthened the inverse relationship between alcohol consumption and CHD in France. Still, our findings indicate that both in France and Northern Ireland most current abstainers can be considered as former drinkers, and that it is quite unlikely that such a large number of subjects quitted drinking because of alcohol-related illnesses. Indeed, the prevalence of alcohol-related diseases (as defined previously) was comparable between former drinkers and real abstainers in both countries (not shown).

Finally, although increased alcohol consumption was associated with a decreased risk of MI in our study, potential hazards associated with heavy drinking complicate any policy recommendation that lifelong teetotallers start drinking or that moderate drinkers increase their consumption. Indeed, after multivariate adjustment and excluding subjects on sick leave, subjects in the highest quintile of alcohol consumption had a significantly higher risk for overall and non-CHD mortality in Northern Ireland than abstainers $[\mathrm{RR}=2.39,95 \%$ CI $(1.13-5.06)$ and $\mathrm{RR}=4.26(1.77-10.21)$ for total and non-CHD mortality, respectively, both $P<0.05]$ but not in France $[\mathrm{RR}=0.85(0.40-1.77)$ and $\mathrm{RR}=0.99(0.42-2.11)$ for total and non-CHD mortality, respectively, both nonsignificant]. Hence, in terms of preventing CHD and regarding overall mortality, we recommend that teetotallers do not start drinking, and that moderate drinkers continue to drink moderately.

In summary, our data indicate that alcohol consumption patterns (as observed in France and Northern Ireland) exert differential effects on CHD risk in middle-aged men from France and Northern Ireland. Further, the amount of alcohol consumption, rather than the type of alcoholic beverage, is related to both angina pectoris and myocardial infarction in France, whereas no similar relationship was found in Northern Ireland.

\section{Acknowledgements}

The PRIME study is supported by grants from Merck, Sharp \& Dohme-Chibret (France) and from the Department of Health and Social Services and the Northern Ireland Chest, Heart and Stroke Association. Please, also refer to reference [16].

\section{References}

1 Uemura K, Pisa Z. Trends in cardiovascular disease mortality in industrialized countries since 1950. Wld H/th Statist Quart 1988; 41:155-178.

2 Husten L. Global epidemic of cardiovascular disease predicted. Lancet 1998; 352:1530.

3 Reddy KS, Yusuf S. Emerging epidemic of cardiovascular disease in developing countries. Circulation 1998; 97:596-601.
4 Jackson R, Scragg R, Beaglehole R. Alcohol consumption and risk of coronary heart disease. BMJ 1991; 303:211-216.

5 Rimm EB, Giovannucci EL, Willett WC, Colditz GA, Ascherio A, Rosner B, et al. Prospective study of alcohol consumption and risk of coronary disease in men. Lancet 1991; 338:464-468.

6 Rimm EB, Klatsky A, Grobbee D, Stampfer MJ. Review of moderate alcohol consumption and reduced risk of coronary heart disease: is the effect due to beer, wine, or spirits? BMJ 1996; 312:731-736.

7 Camargo Jr. CA, Stampfer MJ, Glynn RJ, Grodstein F, Gaziano JM, Manson $\mathrm{JE}$, et al. Prospective study of moderate alcohol consumption and mortality in US male physicians. Arch Intern Med 1997; 157:79-85.

8 Tunstall-Pedoe H, Woodward M, Tavendale R, A'Brook R, McCluskey MK. Comparison of the prediction by 27 different factors of coronary heart disease and death in men and women of the Scottish Heart Health Study: cohort study. BMJ 1997; 315:722-729.

9 Albert CM, Manson JE, Cook NR, Ajani UA, Gaziano JM, Hennekens CH. Moderate alcohol consumption and the risk of sudden cardiac death among US male physicians. Circulation 1999; 100:944-950.

10 Renaud S, De Lorgeril M. Wine, alcohol, platelets and the French paradox for coronary heart disease. Lancet 1992; 339:1523-1526.

11 Goldberg DM. Does wine work? Clin Chem 1995; 41:14-16.

12 Grønbæk M, Sørensen TIA. Alcohol consumption and risk of coronary heart disease. Studies suggest that wine has additional effect to that of ethanol. BMJ 1996; 313:365.

13 Marques-Vidal P, Ducimetière P, Evans A, Cambou JP, Arveiler D. Alcohol consumption and myocardial infarction: a case-control study in France and Northern Ireland. Am J Epidemiol 1996; 143:1089-1093.

14 Gaziano JM, Hennekens CH, Godfried SL, Sesso HD, Glynn RJ, Breslow JL, et al. Type of alcoholic beverage and risk of myocardial infarction. Am J Cardiol 1999; 83:52-57.

15 Marques-Vidal P, Arveiler D, Evans A, Montaye M, Bingham A, Ruidavets $\mathrm{JB}$, et al. Patterns of alcohol consumption in middle-aged men from France and Northern Ireland. The PRIME Study. Eur J Clin Nutr 2000; 54: 321-328.

16 Yarnell JW. The PRIME study: classical risk factors do not explain the several-fold differences in the risk of coronary heart disease between France and Northern Ireland. Prospective Epidemiological Study of Myocardial Infarction. Q J Med 1998; 91:667-676.

17 Rose GA, Blackburn H, Gillum RR, Prineas RJ. Cardiovascular survey methods, 2nd edn. Geneva: World Health Organization; 1982.

18 Ruidavets J, Ducimetière P, Arveiler D, Amouyel P, Bingham A, Wagner A, et al. Types of alcoholic beverages and blood lipids in a French population. $J$ Epidemiol Commun Health 2002; 56:24-28.

19 Ruidavets J, Teissedre P, Ferrières J, Carando S, Bougard G, Cabanis J. Catechin in the Mediterranean diet: vegetable, fruit or wine? Atherosclerosis 2000; 153:107-117.

20 WHO MONICA Project, (prepared by Tunstall-Pedoe H, Kuulasmaa K, Amouyel P, Arveiler D, Rajakangas AM, Pajak A). Myocardial infarction and coronary deaths in the World Health Organization MONICA Project. Registration procedures, event rates, and case fatality rates in 38 populations from 21 countries in four continents. Circulation 1994; 90:583-612.

21 Camargo Jr. CA, Stampfer MJ, Glynn RJ, Grodstein F, Gaziano JM, Manson $\mathrm{JE}$, et al. Moderate alcohol consumption and risk for angina pectoris or myocardial infarction in US male physicians. Ann Intern Med 1997; 126:372-375.

22 Kitamura A, Iso H, Sankai T, Naito Y, Sato S, Kiyama M, et al. Alcohol intake and premature coronary heart disease in urban Japanese men. Am J Epidemiol 1998; 147:59-65.

23 Renaud SC, Guéguen R, Siest G, Salamon R. Wine, beer, and mortality in middle-aged men from Eastern France. Arch Intern Med 1999; 159: 1865-1870.

24 DiPadova C, Worner TM, Julkunen RJ, Lieber CS. Effects of fasting and chronic alcohol consumption on the first-pass metabolism of ethanol. Gastroenterology 1987; 92:1169-1173.

25 Marques-Vidal P, Cambou JP, Nicaud V, Luc G, Evans A, Arveiler D, et al. Cardiovascular risk factors and alcohol consumption in France and Northern Ireland. Atherosclerosis 1995; 115:225-232.

26 Luc G, Bard J, Evans A, Arveiler D, Ruidavets J, Amouyel P, et al. The relationship between apolipoprotein $\mathrm{Al}$-containing lipoprotein fractions and environmental factors: the prospective epidemiological study of myocardial infarction (PRIME study). Atherosclerosis 2000; 152: 399-405.

27 Rimm EB, Williams P, Fosher K, Criqui M, Stampfer MJ. Moderate alcohol intake and lower risk of coronary heart disease: meta-analysis of effects on lipids and haemostatic factors. BMJ 1999; 319:1523-1528. 
28 Gaziano JM, Buring JL, Breslow JL, Goldhaber SZ, Rosner B, VanDenburgh $\mathrm{M}$, et al. Moderate alcohol intake, increased levels of high-density lipoprotein and its subfractions, and decreased risk of myocardial infarction. $N$ Engl $J$ Med 1993; 329:1829-1834.

29 Pearson TA. Alcohol and heart disease. Circulation 1996; 94:3023-3025.

30 Mennen LI, Balkau B, Vol S, Caces E, Eschwège E. Fibrinogen: a possible link between alcohol consumption and cardiovascular disease? DESIR Study Group. Arterioscler Thromb Vasc Biol 1999; 19:887-892.

31 Gaziano JM, Gaziano TA, Glynn RJ, Sesso HD, Ajani UA, Stampfer MJ, et al. Light-to-moderate alcohol consumption and mortality in the Physicians' Health Study enrollment cohort. J Am Coll Cardiol 2000; 35:96-105.

32 Kauhanen J, Kaplan GA, Goldberg DE, Salonen R, Salonen JT. Pattern of alcohol drinking and progression of atherosclerosis. Arterioscler Thromb Vasc Biol 1999; 19:3001-3006.
33 Britton A, McKee M. The relation between alcohol and cardiovascular disease in Eastern Europe: explaining the paradox. J Epidemiol Commun Health 2000; 54:328-332.

34 Marques-Vidal P, Arveiler D, Evans A, Amouyel P, Ferrières J, Ducimetière $\mathrm{P}$. Different alcohol drinking and blood pressure relationships in France and Northern Ireland. The PRIME Study. Hypertension 2001; 38:1361-1366.

35 Klatsky AL, Armstrong MA, Friedman GD. Red wine, white wine, liquor, beer and risk for coronary artery disease hospitalization. Am J Cardiol 1997; 80:416-420.

36 Rosenberg L, Slone D, Shapiro S, Kaufman DW, Miettinen OS, Stolley PD. Alcoholic beverages and myocardial infarction in young women. Am J Public Health 1981; 71:82-85.

37 Kelsey JF, Thompson WD, Evans AS. Methods in observational epidemiology. New York: Oxford University Press; 1986. 